\section{Eco-extractivismo y los discursos de la naturaleza en Patagonia-Aysén: nuevos imaginarios geográficos y renovados procesos de control territorial $^{\star}$}

Eco-extractivism and discourses of nature in Patagonia-Aysén: new geographical imaginaries and renewed territorial control processes

\author{
ANDRÉs NúÑEZ \\ ENRIQUe Aliste ${ }^{* * *}$ \\ Alvaro Bello \\ Juan Pablo Astaburuaga ${ }^{* * * * *}$
}

\footnotetext{
* Los autores agradecen el apoyo de CONICYT a partir de los proyectos FONDECYT N № 1170643 y № 1150770 y del proyecto PIA Anillo Soc 1404

** Instituto de Geografía, Pontificia Universidad Católica de Chile. aanunezg@uc.cl

*** Departamento de Geografía, Universidad de Chile. ealiste@ uchilefau.cl

**** Núcleo de Ciencias Sociales, Universidad de la Frontera. alvaro. bello@ufrontera.cl

${ }^{* \star * \star *}$ School of Environment, Auckland University, New Zealand. jpastabu@uc.cl
}

\section{Resumen}

El presente artículo expone una serie de impactos o procesos de cambio que han surgido en la nueva relación cultura-naturaleza en PatagoniaAysén. Planteamos que la (nueva) Naturaleza no existe en sí misma sino como proyección valórica e identitaria de procesos socio-temporales que reflejan consensos significantes. Formulamos que la nueva retórica geográfica que expresa socialmente a Patagonia-Aysén desde 1990 representa una re-apropiación de la Naturaleza y una nueva matriz interpretativa en torno a ella. Esta matriz no es ajena a lógicas de poder y al desarrollo de mecanismos capitalistas que ven en esta "nueva" Naturaleza enverdecida una oportunidad para negocios específicos, un soporte de producción capitalista que denominaremos aquí como eco-extractivista y, en consecuencia, un nuevo tipo de colonialismo.

Palabras clave: naturaleza, Patagonia-Aysén, capitalismo, eco-extractivismo

\begin{abstract}
This article presents a series of impacts or change processes that have emerged in the new culture-nature relationship in PatagoniaAysén. We argue that (new) Nature does not exist in itself just as a projection of value and identity of socio-temporal processes that reflect significant consensus. We formulate that the new geographical rhetoric that socially expresses Patagonia-Aysén since 1990 represents a reappropriation of Nature and a new interpretative matrix around it. This matrix is not alien to logics of power and the development of capitalist mechanisms which see in this "new" Green
\end{abstract}


Nature an opportunity for specific businesses, a support of capitalist production that we call eco-extractivism.

Key words: nature, Patagonia-Aysén, capitalism, production of space

\section{Introducción}

La presente propuesta se formula desde los intereses y soportes epistemológicos de la geografía social, geografía cultural y geografía histórica. Nuestro objetivo general es analizar y ponderar el proceso de transformación y articulación de la reapropiación socio-cultural de la Naturaleza en Patagonia-Aysén (ver Figura 1) entre 1990 y 2017 y su vínculo con prácticas capitalistas. Esta reinterpretación de la Naturaleza ha ido generando un nuevo imaginario geográfico que sería, desde nuestra perspectiva, un desplazamiento del sentido social del espacio de Patagonia-Aysén así como el despliegue de un proceso de control capitalista que ve "en lo verde" una oportunidad de negocio, proceso que acá hemos denominado ecoextractivismo. El término eco-extractivismo está emparentado con el de eco-colonialismo y busca dar cuenta precisamente de ese nuevo vínculo del capitalismo con las lógicas de conservación de la biodiversidad en Patagonia. Desde este concepto, la "nueva" Naturaleza se torna en valor de uso y de cambio. Los mecanismos de conservación devienen en una evidente especulación en la compra de terrenos por su valor de uso y su valor de cambio. Además, en algunos casos se da un proceso de "proletarización" en cuanto sus antiguos habitantes se ven obligados a asalariarse en el propio negocio turístico que surge desde la definición de una "nueva" Naturaleza "única y exclusiva para el mundo". El concepto de ecoextractivismo está inserto, por tanto, en un proceso globalizante donde los nuevos dueños delastierras "ricas en biodiversidad", representan plataformas de negocios de tipo "verde" donde el "valor" que generan es extraído del territorio patagónico hacia la metrópolis/capital o bien el extranjero para su financiarización ${ }^{1}$.

Esta nueva significación imaginaria retoma y refunda la idea geográfica de la tierra del fin del mundo, donde el lugar paradisíaco y su posición de territorio "virgen" lleva a homologar a estos parajes australes con una "Reserva de Vida" que sería, a su vez, la respuesta de un tiempo globalizado, cargado de imágenes apocalípticas. Aquella construcción social de una "nueva" Naturaleza no corresponde, desde nuestro soporte de análisis, a una representación generada por las características intrínsecas o "naturales" de la zona, sino que es el resultado de un proceso de producción territorial, no ajeno a lógicas de poder de tipo capitalista. Así, la valorización de una "nueva" Naturaleza en un contexto globalizado, sería una renovada colonización del sentido geográfico de los espacios periféricos de la nación? ${ }^{2}$.

Siguiendo un argumento instalado por Moore (2016), la llamada crisis ecológica -que deviene en discursos apocalípticosinaugura un tiempo donde la naturaleza es reintrepretada como "el fin de la naturaleza barata" para poner en cuestión su utilización infinita. Así, la conservación de la naturaleza en Patagonia-Aysén por ejemplo, sería la extensión eco de una renovada movilización capitalista que apunta ahora a hacerse cargo de los "excedentes ecológicos" posicionándose como refugio y reserva de vida... para el mundo, pero, a la vez, para los nuevos parámetros a partir de los cuales se va construyendo un también nuevo equilibrio entre cultura y naturaleza y, por extensión, entre capital y naturaleza.

Desde una perspectiva metodológica, la presente propuesta constituye una reflexión teórica que dialoga con un intenso trabajo de campo (entrevistas, observación) de los últimos años. Desde este punto de vista, responde a la confluencia de un proceso teórico con un trabajo empírico que nos permite comprobar o constatar los estrechos vínculos entre capitalismo y la producción de una "nueva" naturaleza. 
Figura 1. Mapa localización Patagonia-Aysén

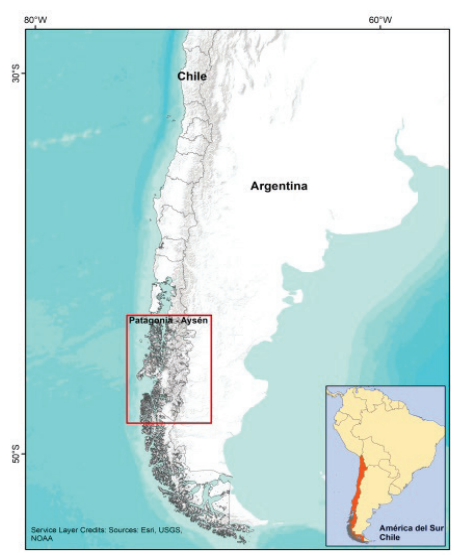

Fuente: Elaboración propia

Este nuevo proceso de significación territorial, donde se han acentuado los discursos en torno a la sustentabilidad ambiental, está gatillando una serie de transformaciones territoriales que reorganizan este espacio austral, permitiendo de este modo visualizar mecanismos discursivos $y$ prácticas que articulan y movilizan estas nuevas dinámicas territoriales. Las más relevantes y de las que nos hacemos cargo son: (a) La (nueva) Naturaleza está inserta en un horizonte de comprensión antes de fijar una existencia en ella misma y, en aquél contexto, es purificada y esencializada; (b) La (nueva) Naturaleza en Patagonia-Aysén, ahora "enverdecida", articula un renovado proyecto Modernizador y de Desarrollo, tanto para la nación como para el mundo; (c) Se produce una mercantilización de la (nueva) Naturaleza que está impactando directamente en una concentración de la propiedad de la tierra por parte de capitalistas que ven allí una oportunidad de negocios; (d) Patagonia-Aysén desde esta "nueva" Naturaleza ratifica y profundiza su condición de periferia y excepcionalidad, ahora a escala global; (e) La (nueva) Naturaleza ha privatizado los bienes comunes que representaba la relación previa de los habitantes con ella.

Planteamos que el proceso de producción social del espacio en Patagonia-Aysén, que fija en una nueva Naturaleza su significado territorial, es vinculante a lógicas de poder capitalistas en la medida que despliegan una serie de estrategias y prácticas que inciden directamente en el devenir cultural (cosmovisión) de la región. Este proceso lo hemos asociado a lógicas de extractivismo y colonialismo clásico pero en clave "eco", en tanto también es un proceso de control territorial, pero donde lo central está en relevar y enmarcar negocios de recursos naturales bajo un lenguaje "ecológico". Conservar, como extraer, corresponden, de acuerdo a nuestra propuesta, a un horizonte común de asociación del capital con los recursos naturales ${ }^{3}$. Nos interesa concluir que la comprensión de la (nueva) Naturaleza es una mirada que le quita lo político y las relaciones de poder a lo ecológico de Patagonia-Aysén. Por lo mismo, estimamos que no se ha puesto suficiente atención a los impactos que el nuevo esquema ontológico en la relación CulturaNaturaleza ha impuesto en Patagonia-Aysén. Lo normal ha sido-y es - quedarse en esa suerte de belleza "natural" de la Naturaleza, pero menos

Es necesario reconocer que en Patagonia-Aysén no hubo un desarrollo industrial ni una formación de clases como en Chile Central u otras áreas donde el capitalismo se instaló con solidez. Sin embargo, la instalación del capital en Patagonia-Aysén, aún poniendo límites a un modelo de tipo extractivista, se comprende, por una parte, en el marco de las "propias contradicciones del capital" (Harvey, 2014) y, por otra, en una renovada producción de rentas monopólicas que deriva e instala a la (nueva) Naturaleza en un verdadero commodity. Como ha expuesto Rodríguez, Reyes y Mandujano: "...la racionalidad capitalista también convierte a la naturaleza en mercancía... creándose un nuevo mercado de consumo de lugares prístinos..." $(2016,190)$. 
atención se le ha prestado a la relación entre Naturaleza y Poder o entre Naturaleza y Capital. De estas relaciones buscamos encargarnos a continuación.

\section{El espacio geográfico, los imaginarios del desarrollo y la reapropiación social de la naturaleza: una tradición en movimiento}

\subsection{La relación cultura-naturaleza en la geografía tradicional}

En lo que puede ser considerado un paradigma, el saber geográfico ha venido comprendiendo al espacio como un objeto, es decir, un espacio donde sujeto y objeto funcionarían en forma independiente. Sería el sujeto, de acuerdo a esa mirada epistemológica, quién se encargaría de describir, localizar, mensurar lo que parecería estar "allí afuera". Desde esa perspectiva, en general los estudios geográficos han invisibilizado el vínculo del sujeto social con la configuración de aquellos espacios y la co-fabricación que, como veremos, implica la imbricación entre sujeto y objeto. Por lo mismo, han minimizado el espacio existencial y relacional, cuyo vínculo con la memoria y con el significado temporal es ineludible (Aliste y Rabi, 2012; Aliste y Núñez, 2015; Núñez et al. 2016).

Por otra parte, en base al mismo supuesto, el saber geográfico ha estado estructurado a partir de la producción de un conocimiento que se articula desde un proyecto de carácter nacional y para lo cual define regiones o zonas con determinadas características, otorgándoles "vocaciones territoriales" que parecen inmutables e inamovibles. De esta suerte, algunas regiones tendrían un destino productivo de tipo minero, forestal o, en el caso del interés de este escrito, de conservación o de "reserva de vida". Como bien sabemos, este modelamiento o fijación del sentido geográfico no considera suficientemente la temporalidad o historicidad de dichos espacios, ya que luego de cumplidos sus ciclos productivos, agotan dichos modelos. En Chile, los casos de la minería del carbón es de los más notorios, pero se le suman las zonas forestales madereras y más recientemente las salmonícolas, por señalar algunas.

En este contexto de definición de la relación entre cultura (sujeto) y naturaleza (objeto), PatagoniaAysén ha sido observada desde esos estudios geográficos como excepcionalidad y periferia a partir de relatos que han centrado su atención, por un lado, en la dimensión política (fronteras interiores) en tanto se remiten a zonas que deben ser incorporadas a la nación de modo inclusivo, identificando en esas espacialidades carencias o problemas que las hacen especialmente vulnerables ("geopoliticamente complicados") desde una mirada marcadamente centralista (SUBDERE, 2008), además de poseer un evidente acento normativo (Nogué y Rufí, 2001; Laurín y Núñez, 2013). Por otra parte, desde una mirada dominada por la geografía física, se ha puesto a Patagonia-Aysén en la órbita de un territorio inerte, estable, es decir, interpretado como naturaleza muerta (Foucault 2010; Lindón y Hiernaux, 2012; Nogué y Romero, 2006). Ha imperado, en definitiva, el argumento que establece que el aislamiento geográfico de las zonas periféricas se soluciona a partir del término de la separación física entre las zonas integradas y las desintegradas o desconectadas (Arenas, Salazar, Núñez, 2011; García Canclini, 2005).

Así, lo común a estas miradas geográficas ha sido (a) una lectura estado-céntrica, es decir, marcan a los espacios regionales como 
periferias que aún no tendrían resueltas "sus lógicas de desarrollo"; (b) que definen verdaderas "vocaciones geográficas" desde una "naturaleza" que pareciera contener en sí mismo su elemento identitario; (c) que observan y comprenden el espacio como realidad física a-temporal (por tanto, carente de historicidad).

\subsection{La noción de cultura/naturaleza y de espacio geográfico en discusión: el espacio socialmente construido}

La investigación geográfica en las últimas décadas, sin embargo, ha venido subrayando y re-valorizando la interpretación de un sujeto social que no puede evadirse de la simbiosis que implica entender que lo geográfico es temporalidad y espacialidad a la vez, así como también es cultura y naturaleza al mismo tiempo (Smith, 1984; Descola, 2012; Leff, 2004; Swyngedoun, 2015; Von Mentz, 2012; Bustos, Prieto y Barton, 2015; Aliste y Urquiza, 2010; Núñez, 2013). Es decir, que la comprensión geográfica tiene subsumida también un modo de visualizar el tiempo y el espacio así como la relación cultura-naturaleza (Gadamer, 1999; Ther, 2012; Vergara, 2010; Ricoeur, 2010, Aliste y Núñez, 2015).

Esta perspectiva cambia profundamente el enfoque y análisis geográfico del problema cultura-naturaleza. En el fondo, interesa más comprender cómo y bajo qué articulaciones los fenómenos físicos, biológicos, en fin, de la "naturaleza", son captados y procesados por las sociedades de modo que la Naturaleza va adoptando valores y significados que se articulan en un contexto temporal:

\footnotetext{
"Cada sociedad construye artificialmente sus estados naturales que aseguran una partición, un reparto y un régimen de relación legítimos (aceptados por la mayoría)
}

entre lo humano y lo no humano, entre lo natural y lo social" (Latour, 2008).

La geografía, por tanto, especialmente desde la década del 80 , ha girado hacia un paradigma donde nuevas preguntas y puntos de vista han formulado renovados enfoques capaces de problematizar tanto aquella clásica definición de espacio geográfico como de ciertos territorios que desde una mirada física o política han sido comprendidos únicamente como áreas de excepción, zonas separadas y diferentes o "en camino a" (Serje, 2011; Escobar, 2012; Alimonda, 2011; Lindón y Hiernaux, 2010, 2012; Di Méo y Buléon, 2005). Desde este punto de vista, los estudios geográficos han ampliado el panorama en un diálogo abierto con las ciencias sociales (Zusman et al. 2011; Nogué y Romero, 2006). De esta suerte, al investigar los espacios llamados marginales, como tradicionalmente se ha definido a PatagoniaAysén, resulta indispensable enfocarse en los procesos de construcción y delimitación de las geografías nacionales/globales "a partir de las metáforas y relatos enunciados por y desde el poder estatal/global que las define" (Serje, 2011). Es decir, espacios que asumen una condición de marginalidad "oficial" (nuevamente cruzados por determinadas "vocaciones") y que, por lo mismo, son naturalizados desde una representación hegemónica que deriva en un imaginario geográfico en cierto modo indiscutible y fijo.

Para nuestro caso de estudio, en lo que puede sonar un juego de palabras, la Naturaleza de Patagonia-Aysén es precisamente naturalizada como "natural"; es decir, es interpretada como esencial de la región (una -ahora sí- "vocación" intrínseca) y, a su vez, es purificada desde una posición que la torna universal y a-temporal. Al respecto, Swyngedow señala en relación a 
esto que no es posible definir la Naturaleza, por lo que todos los esfuerzos e intentos de establecer su sentido, son en vano o políticamente problemáticos. De esta forma, la Naturaleza se presenta como un "significante "flotante" y "vacío" (...)Se convierte en un revestimiento, un montaje de sentido..." (Swyngedouw, 2015, 33)8.

Desde este punto de vista, estimamos que para estudiar la relación sociedad-naturaleza en Patagonia-Aysén es necesario también reconocer el saber geográfico como un campo de producción social y como horizonte de una memoria que es, como fue expresado, "flotante" o fugaz (Núñez, Aliste y Arenas, 2017a). Por lo mismo, indagar en las rutas y engranajes a través de las cuales la nación (centro) o el sistema-mundo se relaciona con sus espacios periféricos, donde fija excepcionalidad y diferencia, es decir, una "naturaleza" que requiere ser delimitada, es también un asunto de contextos y de definición de tipos de versiones de lo que se va comprendiendo por "La Geografía" de Patagonia-Aysén. Por ello si buscamos entender los nuevos procesos de cambio en Patagonia-Aysén se requiere indagar en la parte política del capital y en la generación de relatos sociales sobre la base de los cuales se definirán los soportes de la matriz disciplinaria que establece que Patagonia-Aysén es una "Reserva de Vida" y que su Naturaleza es sustancial para "la vida".

En definitiva, investigar el rol de la "nueva" Naturaleza en Patagonia-Aysén compromete no perder de vista la dimensión técnica y estratégica de la objetivización de la Naturaleza, es decir, la articulación surgida desde el ámbito del poder/ capital, nacional o global, como los impactos que estos nuevos procesos discursivos generan.

\section{La Naturaleza "verde" como nueva metáfora geográfica en Patagonia-Aysén}

En la década de 1980 Patagonia-Aysén aún se asociaba a los procesos de colonización que marcaron su devenir geográfico durante gran parte del siglo ${ }^{4}$. Sin embargo, la década de 1990 viene a madurar un proceso al que no se le ha prestado la suficiente atención: la instalación de una (nueva) Naturaleza como soporte geográfico de una identidad social que ha llevado a homologar a Patagonia-Aysén con la idea de una "Reserva de Vida".

Esta trayectoria identitaria, con notable fuerza y rapidez, se inscribe, sin renunciar al contexto de un imaginario geográfico de escala nacional, en una afiliación transnacional/global que promueve una serie de prácticas y acciones que generan nuevos imaginarios del desarrollo y cambios en las relaciones con el medio ambiente regional (Núñez, Aliste y Bello 2014; Mellado, 2015; Rodríguez y Sáenz, 2017). Este aspecto es esencial: así como Patagonia-Aysén durante todo el siglo $X X$ fue el reflejo de una interpretación nacional (centro-periferia), de lo que derivó una significación de un territorio aislado, no incorporado, ausente, a conquistar, etc., hacia 1990 Aysén se inserta en un proceso discursivo de escala global, lo que resultaría vital para justificar su -nuevamente- condición de excepcionalidad/periferia, pero esta vez en base a una valorización de una Naturaleza que es también mundial.

Como deseamos demostrar acá, los nuevos discursos de la Naturaleza en PatagoniaAysén no serán, como podría pensarse, un

De hecho, de 1989 es el último Programa de Colonización Inducida, llamado que hace el Ministerio de Bienes Nacionales para ocupar nuevos territorios. 
panorama neutro donde la clave esté siendo la conservación o resguardo de una naturaleza univalente. Ello es relevante sin duda, pero lo novedoso desde nuestro punto de vista, es preguntarse por el alcance, los marcos sociales y los impactos de aquella nueva racionalidad ambiental así como su vínculo ineludible con prácticas capitalistas:

\begin{abstract}
"La biodiversidad aparece no solo como una multiplicidad de formas de vida, sino como reservas de naturaleza -territorios y hábitat de diversidad biológica y cultural-, que están siendo valorizados por su riqueza genética, sus recursos ecoturísticos y su función como colectores de carbono" (Leff, 2004, 113).
\end{abstract}

En el fondo, "lo verde" en Patagonia-Aysén se ha ido transformando en un discurso de carácter utópico, por ende ideológico (Foucault, 2010; Castree, 1995 y 2005), cuyo soporte ha sido también una tecnología de poder que ha impactado de modo radical en los espacios locales y en los procesos de madurez de nuevos imaginarios geográficos ${ }^{5}$.

La "nueva" Naturaleza en Patagonia-Aysén, en tanto supone una renovada relación hombremedio, se instala como una administración que no solo incluye las (también nuevas) reglas desde donde el hombre puede relacionarse con ella (por ejemplo, no quemarla, no destruirla, etc.) sino, a su vez, un horizonte de comprensión donde se asienta lo que Maturana ha llamado el lenguajear, es decir, interacciones estructurales que hacen que los participantes con sus prácticas y modos de expresarse generen consensos y modos de racionalidad fijados por el lenguaje:

Al hablar de "imágenes geográficas" lo expresamos en el sentido dado por Castoriadis (2010): estructuras históricas sólidas que organizan la sociedad definiendo su horizonte y significación social. “...el lenguaje como proceso no tiene lugar en el cuerpo (sistema nervioso)... sino que es el espacio de coordinaciones conductuales consensuales que se constituye en el fluir de sus encuentros corporales recurrentes" (Maturana, 2009, 20).

En otras palabras, decir "Aysén, Reserva de Vida" es proyectar una práctica hablada que da cuerpo y sentido a lo que vamos entendiendo por Naturaleza. Así como lo "humano" de la humanidad surge en y desde el lenguaje, lo "natural" de la Naturaleza se asienta en el mismo proceso cognitivo. Lo anterior es relevante para entender las nuevas formas de aprehensión y producción social de la (nueva) Naturaleza en Patagonia-Aysén. De este modo, para comprender la (nueva) Naturaleza en PatagoniaAysén es necesario también introducirse en los efectos que este lenguaje social implica.

Así, cuando la Naturaleza en Patagonia-Aysén ha dejado de ser un obstáculo para el desarrollo ganadero, como lo fue durante gran parte del siglo XX, cuando la Naturaleza retoma, aunque ahora "enverdecida", su trasfondo teleológico, cuando la Naturaleza aparece como generadora de "vida" y respuesta a los múltiples miedos de la sociedad (el cambio climático o los desastres -precisamente-naturales, entreotros), nos parece vital subrayar algunos aspectos colaterales resultantes de la instalación significante de una Naturaleza que se re-interpreta como "Reserva de Vida" y como fuente de bio-diversidad. Como ya adelantamos, los aspectos centrales que abordaremos en este trabajo respecto de Patagonia-Aysén son:

(1) La (nueva) Naturaleza en Patagonia-Aysén no corresponde a una representación generada por las características intrínsecas o "naturales" de la zona sino que es el resultado de un proceso de 
producción territorial donde la relación cultura-naturaleza se desarrolla como co-fabricación o co-pertenencia entre el sujeto y el paisaje que él mismo construye al mismo tiempo que lo constituye como sujeto. Así, la Naturaleza está inserta en un horizonte de comprensión antes de fijar una existencia en ella misma.

(2) La (nueva) Naturaleza se instala como un renovado proyecto de Modernidad y de Desarrollo que viene a justificar una serie de cambios instalados en Patagonia-Aysén.

(3) La (nueva) Naturaleza es un soporte para mercantilizar a la Naturaleza, para generar grandes cambios especulativos en torno a la propiedad de la tierra.

(4) La (nueva) Naturaleza ratifica la condición de periferia y excepcionalidad con que Patagonia-Aysén fue interpretada desde el siglo XIX en las narrativas nacionales, pero ahora en clave global.

(5) La (nueva) Naturaleza ha privatizado los bienes comunes que representaba la relación previa de los habitantes con ella.

\subsection{Patagonia-Aysén: una naturaleza interpretada como naturaleza purificada}

Patagonia-Aysén fue el escenario, como es sabido, de grandes quemas o roces, como eran Ilamadas. Ellas eran indispensables para despejar territorios que tenían, según el devenir de la época, una "vocación ganadera" (Imagen $N^{\circ} 1$ ). En la práctica, era el propio Estado quién sustentaba el carácter obligatorio de tal acción:

"El arrendatario, con un título de carácter provisional, deberá despejar al menos 100 hectáreas. Si al cabo de un año no se encuentra despejada, el ocupante no podrá continuar con el trámite de Titulo Definitivo" (AMTC, 19411948).
La Naturaleza, desde esta base interpretativa tenía -de hecho lo tuvo durante gran parte del siglo XX- una carga valórica negativa. En otras palabras, el bosque, desde aquella comprensión, era un escollo para lo que se comprendía por "progreso", era un impedimento para incorporar tierras periféricas al desarrollo de la nación.

\section{Imagen $N^{\circ} 1$ Bosque quemados o "roces".}

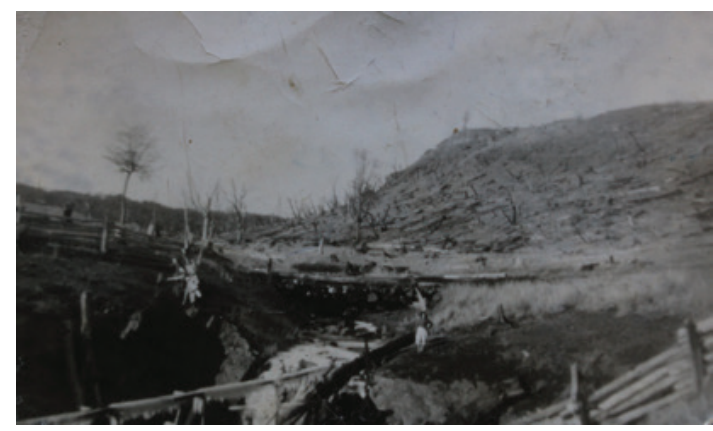

Fuente: Proyecto de investigación "Recuperación de archivos fotográficos familiares, región de Aysén". Fondart - 2014. Investigadora Patricia Carrasco.

La cosmovisión del Estado, sus prácticas y de la sociedad de ese tiempo configuraron el paisaje del colono, del pionero y del patriota y de una Naturaleza hostil y desfavorable. Por tanto, un árbol derribado era una conquista que validaba y actualizaba las vías y estrategias a través de las cuales la nación podía sostener la mirada de un horizonte común, buscando dar fuerza a la ilusión de la identidad nacional, como una suerte de "sueño homogéneo" (Bhabha, 2010). Más allá incluso, derrotar a aquella "Naturaleza inservible" era la metáfora indispensable para proyectar que la nación era todavía un proyecto y que a través del despeje y limpieza de esos bosques Patagonia-Aysén podía llegar a ser reconocida como "nacional". 
Aquel paisaje de una Naturaleza que era escollo y estorbo fue, entonces, el lenguaje y cosmovisión de un enunciado social que expresaba formas e identidades ancladas en un imaginario geográfico común que normalizaba la mirada o comprensión de la Naturaleza (Deleuze y Guattari, 2002). En otras palabras:

\begin{abstract}
"Las miradas sobre el paisaje -y el mismo paisaje- reflejan una determinada forma de organizar y experimentar el orden visual de los objetos geográficos en el territorio. Así, el paisaje contribuye a naturalizar y normalizar las relaciones sociales y el orden territorial establecido" (Nogué, 2009, 12).
\end{abstract}

En el devenir de la relación cultura-naturaleza en Patagonia-Aysén, la Naturaleza adquirió nuevas interpretaciones (Descola, 2012). Así, con el cambio de década de 1980 a 1990 comienza un nuevo proceso en aquél vínculo. En efecto, se fue instalando una renovada matriz interpretativa donde esta vez la Naturaleza fue el objeto que vino a canalizar nuevas inquietudes sobre el medio ambiente, no ajenas, por cierto, a lógicas políticas/capitalistas. De hecho, en la Estrategia Regional de Aysén, elaborada en 2009 por el Gobierno Regional, aún vigente, se estipula que:

\footnotetext{
"La calidad medioambiental de la región de Aysén constituye una ventaja competitiva que debe ser resguardada para sustentar la producción de bienes y servicios de todo tipo, pero en particular, de aquellos vinculados a la industria turística de intereses especiales. Consecuentemente con ello, la región ha adoptado el eslogan Aysén Reserva de Vida" (GORE, 2009).
}

Desde esta perspectiva, la Naturaleza -nuevamente instalada como objeto- fue requerida por el Estado y sus políticas públicas, pero esta vez "para purificar su contenido" (Jazeel, 2014: 79). Es decir, a la (nueva) Naturaleza se le asocian nuevos anclajes sociales que permitan justificar su renovado rol de Reserva de Vida:
"En el lenguaje medioambiental actual, la biodiversidad, las ecociudades, los contaminantes, el CO2, pueden ser pensados como los puntos de anclaje (o point de capiton) mediante los cuales se fija una cierta matriz de sentido de la Naturaleza" (Swyngedouw, 2015, 34).

En el fondo, la (nueva) Naturaleza de PatagoniaAysén, "enverdecida", se instala, como ya expresamos, como un discurso de carácter utópico, en el sentido dado por Foucault al término:

\footnotetext{
"Las utopías son los emplazamientos sin lugar real. Son los emplazamientos que mantienen con el espacio real de la sociedad una relación general de analogía directa o invertida. Es la sociedad misma perfeccionada o es el revés de la sociedad, pero de todos modos, esas utopías son espacios que fundamentalmente, esencialmente son irreales" (Foucault, 2010, 69).
}

Es decir, se sitúa a la Naturaleza provista de una existencia independiente, con una racionalidad propia, cuyo carácter estable, armónico, ético y universal es servir de soporte a una humanidad globalizada para encauzar un nuevo devenir (Imagen $\mathrm{N}^{\circ}$ 2). Este nuevo devenir está mediado por la necesidad de reorientar los males que la propia sociedad le ha causado a la misma Naturaleza. Por lo mismo, ese carácter universal no es, por cierto, ajeno a los miedos surgidos en los contextos de cambio climático $\mathrm{y}$, en cierto modo, apocalípticos de, precisamente, una Naturaleza que se rebelaría a acabarse. La "reserva de vida" es, entonces, una respuesta a esos miedos. 
Imagen $\mathbf{N}^{\circ} \mathbf{2}$ La Naturaleza de Patagonia-Aysén como soporte de una identidad universal

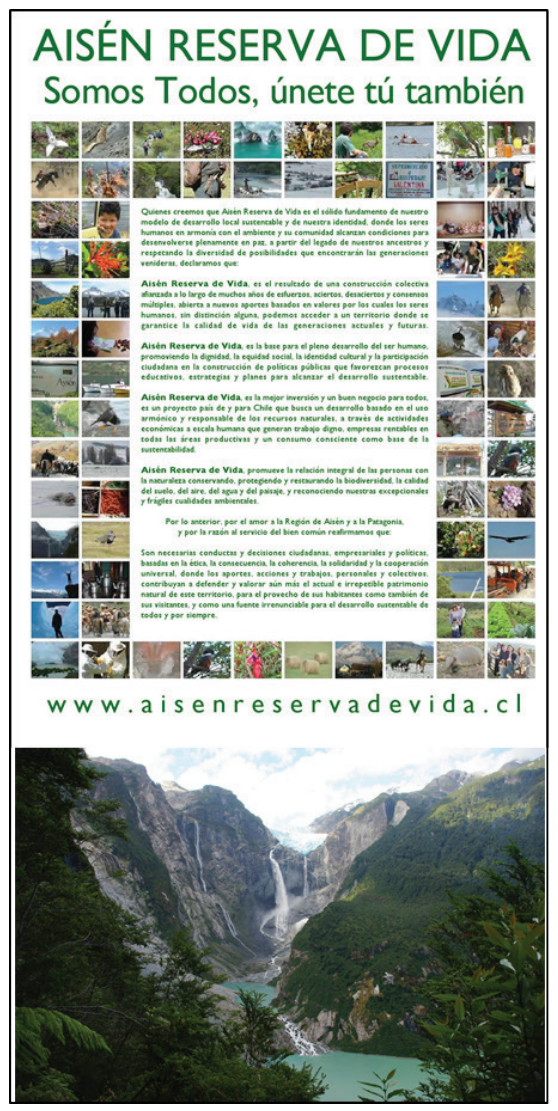

Fuente: www.aisenreservadevida.cl

\subsection{La (nueva) Naturaleza se instala como un renovado proyecto de Modernidad y de Desarrollo}

Como expresamos, triunfar sobre la Naturaleza salvaje y despejar el bosque durante gran parte del siglo $X X$ fue en Patagonia-Aysén sinónimo de Progreso y Desarrollo. Así, por ejemplo, en 1976 la Carretera Austral, una obra inmensa que permitiría conectar de norte a sur la región, se justificaba y promocionaba del siguiente modo:

\footnotetext{
“...una gesta colosal ejecutada sobre una Naturaleza particularmente adversa e inhóspita, que trascenderá en el tiempo", pues, "por el hecho de haber horadado la roca y removido la tierra con el fin de abrir una senda para potenciar el desarrollo social y económico, esta hazaña tendrá la permanencia de las grandes realizaciones del hombre" (García, 1989).
}

Aquellas palabras no eran inocuas, ya que la relación entre polos de interpretación como Naturaleza o Desarrollo, entre Irracionalidad o Razón, entre Adversidad o Hazaña, entre Frontera Interior oSoberanía, entre Caosu Orden, se transformaron en el núcleo fundamental del enunciado social con que fue expresada aquella relevante obra vial. Desde aquella perspectiva, el enfoque de una Naturaleza que debía ser útil al desarrollo y estar disponible para el progreso de la nación fue un gran despliegue de lo que debía comprenderse precisamente por Naturaleza. La Naturaleza, en este marco de prácticas y discursos, fue considerada un desafío a superar, un problema para aquel desarrollo y para la unión de la nación. El bosque, desde aquella comprensión, se presentó como un obstáculo para lo que se entendía por "progreso". De allí que en 1982 en la inauguración de un tramo de la Carretera Austral, la derrota de la Naturaleza permitiese precisamente "abrir" el camino hacia la Modernidad y el Desarrollo:

\footnotetext{
"Hoy cuando vemos cumplido un sueño acariciado por años, cuando sólo el canto del hacha y el martillo del colono de ayer se escuchaba en la inmensidad y soledad de esta Patagonia, cuando la Naturaleza salvaje y agreste parecía no ceder para dar paso a la vía y al progreso, la visión de un hombre, de un soldado, ha vencido nuevamente en una lucha tenaz, constante, fuerte e inteligente y aquello que parecía imposible es hoy una realidad" (Diario Aysén, 1982, 2).
} 
El lenguaje modernizador de un ser humano que lograba controlar a aquella Naturaleza caótica y salvaje se instaló incluso aún en la década de 1990 cuando al arribo de Douglas Tompkins, empresario conservacionista y defensor de un nuevo vínculo del ser humano con la Naturaleza, numerosas personalidades públicas expresaron su opinión. Entre otros, Eduardo Hartwing, vicepresidente de las industrias madereras indicaba: "Tiene criterio anti-desarrollo. Ha sido como un elefante irrumpiendo en una cristalería" (La Tercera 13/07/97); Víctor Hugo Puchi, de los salmoneros decía: "Impone pobreza a los demás" (La Tercera 13/07/97). Por su parte, en 1997, el gerente general de Enersis, la principal empresa de generación energética del país, José Yuraszeck exclamaba:

"Si alguien no quiere energía hidroeléctrica ni termoeléctrica, cabe preguntarse ¿cómo se imagina el Sr. Tompkins que el país pueda desarrollarse? (...) Chile necesita energía y Tompkins está en contra de la energía y del desarrollo del país" (La Tercera, 13/07/97).

Sin embargo, al cabo de unos pocos años, aquellos mismos bosques fueron reflejando un nuevo proyecto modernizador: antes, naturaleza salvaje que la colonización debía domesticar para la nación, desde la década de 1990, naturaleza mágica y de ensueño que había que resguardar para el mundo. En efecto, en Patagonia-Aysén se instala un nuevo engranaje sociodiscursivo que viene a ser articulado por lógicas y consensos conservacionistas, donde el significado de la Naturaleza no será otro que el de otorgar vida para la humanidad. Esa proyección es, del mismo modo que los discursos de la modernidad y del desarrollo previo, una mirada "al futuro" y desde ese punto de vista aparecen en el horizonte de una nueva lectura teleológica que los sustenta.
En 2017 la propia Presidente de Chile, Michelle Bachelet, exclamaba: "¡Gran día para Chile! La visión de Tompkins y la voluntad y aportes del Estado crean la Red de Parques Nacionales de la Patagonia (...) el mayor proyecto de parques terrestres...estamos legando al país la mayor creación de áreas protegidas de la historia..." (BBC Mundo, 17/03/2017) 6 . En este contexto, la Naturaleza se instala ahora como protagonista y elemento central que articula aquella imponente acción público-privada.

Por lo tanto, la "nueva" Naturaleza en PatagoniaAysén, en tanto "Reserva de Vida", viene a reflejar un nuevo rumbo de una también nueva Modernidad. De hecho, la oportunidad para alcanzar esa renovada modernidad se instala en Patagonia-Aysén desde el laboratorio "natural y prístino" que implica su condición de fin de mundo y de nueva frontera del sistema-mundo. La Naturaleza, entonces, se transforma en el resorte para nombrar y justificar el desarrollo como sustentable, lo que junto con marcar la pauta del nuevo discurso modernizador aporta a su vez con "una planificación despolitizada", donde no habría cabida para el disenso (Swyngedouw, 2015; Keucheyan, 2016). En otras palabras, la Modernidad de la nueva Naturaleza en Patagonia-Aysén estaría precisamente en la implementación de sí misma como Modernidad, es decir, como renovada forma de colonialidad de un saber-poder-ser de una Naturaleza que no solo contiene en sí misma el elemento modernizador, sino que viene a ser una respuesta final que busca posicionarse no en los bordes epistémicos sino en el centro mismo del conocimiento (Gregory, D. 2001, Huggan,

\footnotetext{
La Red de Parques a que hacía mención es la suma de áreas privadas y públicas que se destinarán a la conservación en las regiones de Aysén y Magallanes y que supondrán más de 4 millones de héctareas de protección oficial.
} 
y Tiffin, 2007). Sin embargo, como veremos a continuación, en una "sociedad de consumo", con un capital movilizado globalmente, la (nueva) Naturaleza también se transforma en un bien de consumo que puede ser transado en el mercado (Keucheyan, 2016; Ayala y Moritz, 2012; Azam, Bonneuil y Combes, 2012). En el siguiente segmento expondremos con mayor fuerza los alcances de lo que hemos denominado eco-extractivismo. En el fondo, la Naturaleza se instala como una oportunidad competitiva que permite, a través del turismo de intereses especiales, la venta de carbono, la transacción de tierras, la propia conservación, entre otros, fijar una estrecha e inevitable relación entre capital y la "protección" de "ella". Las lógicas de la colonialidad en la trilogía planteada por los estudios descoloniales (Quijano, 2000; Mignolo, 2014) de domesticación de un saberpoder-ser, que se impone como universal puede ser replicada a los procesos que la (nueva) Naturaleza proyecta para Patagonia-Aysén.

\subsection{Mercantilización de la Naturaleza, especulación en la propiedad de la tierra.}

En mayo de 2011, las autoridades del gobierno del entonces presidente Sebastián Piñera aprobaron HidroAysén, uno de los proyectos hidroeléctricos más controvertidos de las últimas décadas en Patagonia-Aysén. En abril de ese mismo año, el $61 \%$ de los ciudadanos chilenos ya había expresado su rechazo a la iniciativa, aunque el proyecto fue finalmente aceptado. En 2014, un nuevo gobierno encabezado por la presidente Michelle Bachelet anuló aquella aprobación en consideración de la "irreversibilidad de los daños al medio ambiente que el proyecto traería" (Emol, 2014). Este "exitoso" episodio en la historia de los movimientos medioambientales en Chile, representaba, en el fondo, el triunfo de la defensa de un territorio caracterizado por su "naturaleza virgen y pura" (MBN, 2014, Romero, 2014). La pregunta que surge es: ¿qué fue lo que hizo, en el fondo, que la "vocación" conservacionista (o este tipo de relación cultura-naturaleza) se impusiera al proyecto energético de tipo extractivista?

Una de las hipótesis que planteamos es que efectivamente la Naturaleza como "capital natural" fue visibilizada por una serie de empresarios (el propio Douglas Tompinks entre ellos) que comenzaron a ver en "lo verde" un nicho de negocio tan particular como atractivo y relevante. Así, el mismo año 2014, de modo muy ilustrativo, la firma chilena Patagonia Brokers comentaba a propósito de su rol en las transacciones de tierra en Patagonia-Aysén que "hoy es más difícil encontrar un empresario que no tenga terreno aquí, que descifrar quiénes sí tienen" (Revista Capital, 2014). Así, aquella extendida tesis que nos indica que el sistema capitalista es incompatible con la conservación de los ecosistemas, perdería peso si observamos y buscamos comprender los soportes geo-históricos del actual despliegue imaginario-geográfico de este territorio austral. Una explicación para entender la madurez o solidez de este binomio capital-conservación de la Naturaleza, es factible buscarla en las, como dice Harvey, propias contradicciones del capital:

\footnotetext{
"Si hay problemas graves en la relación capital-naturaleza, se trata de una contradicción interna y no externa del capital. No podemos sostener que el capital tiene el poder de destruir su propio ecosistema al tiempo que negamos arbitrariamente que tiene un poder potencial similar para sanearse y resolver o cuando menos equilibrar debidamente sus propias contradicciones" (Harvey, 2014: 253).
} 
En otras palabras, el capital es capaz de reinventar su relación con la Naturaleza en territorios específicos. Patagonia-Aysén es uno de ellos $y$, por ende, aparece desde aquella perspectiva en la balanza del equilibrio del ecosistema capitalista. Desde este punto de vista, se transforma en un eco-extractivismo ${ }^{7}$. Es decir, la Naturaleza en Patagonia-Aysén deja de ser, como ha expuesto la geógrafa Alicia Laurín, "un factor de producción para transformarse en un factor de riqueza" (Laurín, 2015) (Imagen $N^{\circ}$ 3). Su planteamiento es muy interesante y acorde a nuestro argumento. En primer lugar, la conservación de la naturaleza no es un proceso neutro o únicamente biológico, es a su vez político y posee intereses desde el poder/capital. En segundo lugar, el capital, como adelantaba Harvey, produce territorios universales, bajo categorías de Reserva, ya sea de Vida o de la Biósfera. Por último, la riqueza "conservada" se posiciona como espacialidad de la globalización, del sistema-mundo (Laurín, 2015). En el fondo, la "Vida" implícita en la condición de Reserva abstrae o succiona lo que hay en las prácticas o "realidad" de esos territorios. Ya volveremos y profundizaremos esta idea en el siguiente apartado.

Grosfoguel (2016) ha planteado que la comprensión de lo que define al extractivismo puede instalarse también desde otros prismas. Por lo pronto, con "extractivismo epistemológico" y "extractivismo ontológico". En todos estos planos, incluso en el asociado al únicamente económico, el extractivismo presenta, como bien apunta, a "una actitud de cosificación". Si bien agrega la palabra "destrucción", estimamos que desde la perspectiva de la cosificación, objetividad o instrumentalización de lo que conocemos por naturaleza, es factible realizar el puente con las perspectivas conservacionistas de apropiación de la "nueva" naturaleza.

\section{Imagen $\mathrm{N}^{\circ} \mathrm{3}$}

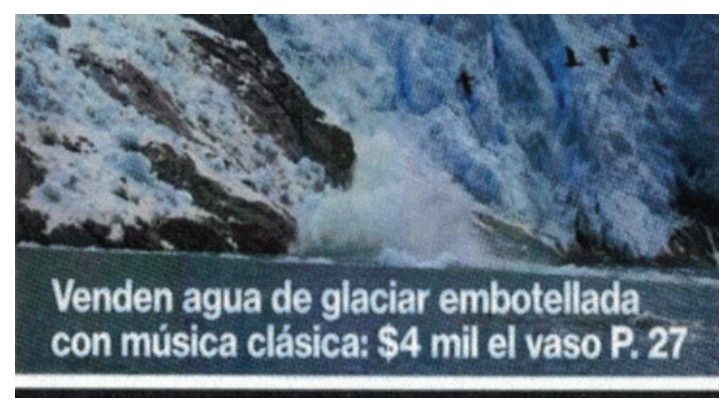

Fuente: La Segunda. 13/04/2015

Aquél, entonces, eco-extractivismo, es decir, aquella reestructuración del capital en su relación con la Naturaleza en Patagonia-Aysén, restructuración que impone un saber, un poder y ser "verde" y sustentable, implica una alianza con el Estado que colabora a privatizar (Sassen, 2015) y mercantilizar la propia Naturaleza así como a fijar un horizonte cultural que termina siendo válido para el conjunto de la población:

"El discurso del desarrollo sostenible se vuelve como un boomerang, decapitando al ambiente como concepto que orienta la construcción de una nueva racionalidad social. La estrategia discursiva de la globalización se convierte en un tumor semiótico y genera la metástasis del pensamiento crítico; disuelve la contradicción, la alteridad, la diferencia" (Leff, 2004, 108).

En ello, el capital mundial ha actuado desde la reapropiación del sentido territorial de Patagonia-Aysén siendo capaz de movilizarse, en sociedad con el Estado nacional, para convertir a la Naturaleza en mercancía y negocio "sustentable".

Este atractivo objeto-naturaleza convertido en riqueza y medio de producción (fundamentalmente en el ámbito del turismo 
de intereses especiales, la venta de huellas de carbono, especulación de la tierra y en el espacio ideal para realizar negocios globales), era hasta hace solo veinte años inexistente. Junto a la inserción de Chile en una economía globalizada, propiciada por la dictadura militar y afianzada por los siguientes gobiernos, aquella nueva relación capital/naturaleza se vino a potenciar además con la construcción de la Carretera Austral, que dejó al descubierto una zona que parecía impenetrable, con recursos "naturales" de gran valor ecológico a nivel mundial (Rodríguez, Medina y Reyes, 2014, Reyes y Rodríguez, 2015; Urrutia, 2017). Esta "utopía verde" de tipo capitalista, en consecuencia, impone una serie de tácticas, mecanismos, formas y prácticas que fijan las reglas de esta renovada relación de lo humano y no humano (cultura-naturaleza) así como la comercialización de la Naturaleza cuyo sentido "patagónico" y de "fin de mundo" requiere ser puesto en valor.

Una de las caras más visibles de aquella nueva re-apropiación de la Naturaleza en PatagoniaAysén ha sido el proceso especulativo y la concentración de la propiedad de la tierra, que nos lleva a formular que sería uno de los soportes indispensables para afianzar un discurso de tipo global-capitalista de corte ambientalista. Un ejemplo de lo que exponemos, de profundas implicancias socio-territoriales, lo observamos en la comuna de Villa O'Higgins, en el extremo sur de Patagonia-Aysén, donde es posible evidenciar la concentración de tierras por parte de una serie de sociedades anónimas, pero especialmente de Las Margaritas S. A. (Figura $\mathrm{N}^{\circ} 2$, en color rojo), empresa de corte conservacionista y liderada por el Grupo Luksic, uno de los más ricos de Chile y del mundo y dueño de una serie de iniciativas extractivistas de tipo clásico en otros lugares del planeta.
Figura $\mathbf{N}^{\circ}$ 2. Cambio propiedad de la tierra, Villa O'Higgins

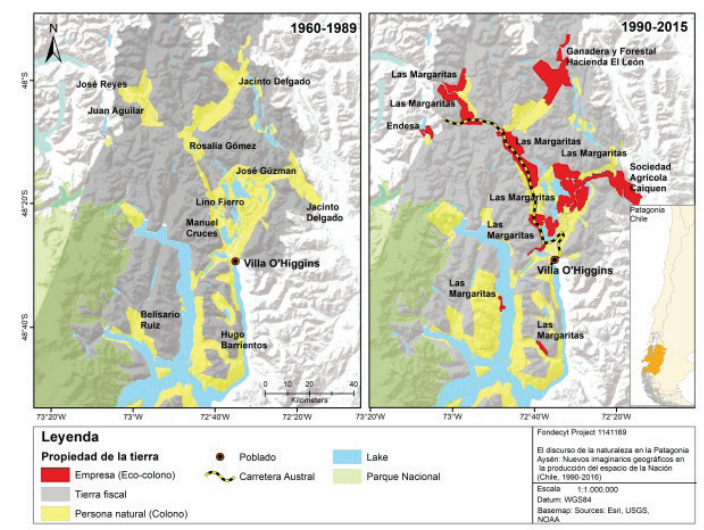

Fuente: Fondecyt $N^{\circ} 1170643$, trabajo en el Conservador de Bienes Raíces de Cochrane (CBRAysén)

\subsection{La (nueva) Naturaleza ratifica la condición de periferia y excepcionalidad con que Patagonia-Aysén fue interpretada desde el marco nacional, pero ahora en clave global.}

Uno de los planteamientos de fondo de lo que hemos venido exponiendo es que PatagoniaAysén ha sido históricamente producida desde una posición diferenciada (centro-periferia) que ha impuesto valores territoriales jerarquizados (Said, 2010; Todorov, 2012; Bhabha, 2010) ${ }^{8}$. Así, durante prácticamente todo el siglo XX fue interpretado como "un territorio aislado" y el discurso de integración fue la justificación

Al respecto, Casini (2005) parafraseando el término Orientalismo definido por Said para exponer la invención que hace Occidente de Oriente, propone el término Patagonialismo para remitirnos a un espacio que es producido como un escenario exótico y periférico, un lugar extraño en cierto modo, y que a luz de su condición actual de "Reserva de Vida" se torna aún más exótico, diferente y fronterizo. 
permanente de su conquista y control. Esta tesis de fondo, a diferencia de lo que pudiese pensarse, no parece haber variado con el nuevo paradigma de tipo conservacionista. En efecto, el nuevo discurso de la Naturaleza en Patagonia-Aysén ha reafirmado y profundizado aquella condición de territorio periférico. Sin embargo, y esto es novedoso desde nuestro punto de vista, aquella valorización negativa ("aislado", "fronterizo", "poco conectado") se ha transformado, en un contexto globalizado, en una característica positiva en el marco del sistema-mundo. Es decir, desde la escala global Patagonia-Aysén ha requerido de su condición de "aislamiento" para justificar una posición de exclusividad en el mundo y su posición de "fin de mundo" ha mutado en el carácter que le confiere ser "reserva" de "vida".

Desde esta perspectiva, nos parece indispensable observar el fenómeno en Patagonia-Aysén bajo el siguiente indicio: la nueva colonización del sentido de la Naturaleza en Patagonia-Aysén, en base a su resguardo y conservación, no responde sino al mismo patrón de producción de diferencias territoriales (espacios fronterizos, "reservas de vida") cuyo texto social está definido desde una centralidad que conjuga lo nacional/global. Lo nacional, debe comprenderse, actúa subsumido en clave global, es decir, el Estado nacional es "privatizado" desde el discurso de la movilidad de capitales a escala global. Lo "verde" de esta nueva Naturaleza, por cierto, no es ajeno a aquello.

La racionalidad ambiental, en consecuencia, "se forja también en una ética de la otredad y una política de la diferencia" (Leff, 2004). Surge así, un territorio que siendo específico es, como ya expresamos, a su vez universal, en tanto se transforma en una espacialidad que trasciende a la nación y se inserta en los campos de un horizonte globalizado (Laurín, 2015). Aquí, las Reservas de la Biósfera, los (nuevos) Parques Nacionales -ahora centrados en su valor en la biodiversidad- y las, aunque sin base legal todavía, Reservas de Vida (Patagonia-Aysén) son un renovado resorte de la expresión geográfica de identidades sociales y culturales basadas en una racionalidad ambiental que adquiere un protagonismo antes no visto. Este territorio universal sería, en el fondo, una continuidad fronteriza, aunque ahora se desplieguen en base a nuevas estrategias discursivas y nuevas tecnologías de poder. Como ha expuesto Harvey:

"La valorización de la naturaleza, o como prefieren conceptualizarlo los economistas ecológicos, el valor monetario del flujo de servicios que la naturaleza ofrece al capital, es arbitrario...Los beneficios ecológicos están localizados en alguna otra parte" (Harvey, 2014, 251).

\subsection{La (nueva) Naturaleza ha privatizado el uso de los bienes comunes que representaba la relación previa de los habitantes con ella.}

El problema central que subyace en este sección es que la protección y conservación de la Naturaleza en Patagonia-Aysén en los rangos que se ha instalado en las últimas dos décadas, se ha trasformado en excusa y justificación de una "necesidad" de formas de administración territorial que sin ellas serían tierras sin valor o, al menos, desprovistas de "utilidad" (que de modo comunitario se pierden y no generan ganancias). En este marco, se ha venido asistiendo a una suerte de renovada privatización de la Naturaleza, coaptada, por un lado, por el discurso de corte universalista a que ya hicimos mención, pero, por otra parte, en el mundo de "lo real", como diría Zizek 
(2013), por el cuestionamiento de formas de vida, de prácticas y tipos de relación sociedad/ naturaleza que no son compatibles con aquellas también nuevas formas de administración. Entre otras, podemos mencionar a las "veranadas" (pastizal de verano de los animales), las diversas utilidades del bosque, códigos de uso de la tierra, la práctica del uso de senderos o huellas históricas.

De esta suerte, el nuevo discurso de la Naturaleza en la región de Patagonia-Aysén, históricamente definida como Frontera Interior, ha gatillado el surgimiento de numerosos espacios fragmentados donde antes había una práctica de "bien común". En otras palabras, así como antes fue en nombre del Desarrollo o de Progreso en el resto de la nación, hoy en nombre de la Naturaleza en Patagonia-Aysén se ha llenado de cercos y formas exclusivas de control territorial, ya sean Redes de Parques o predios particulares cuyo destino se ha volcado hacia la conservación. Es decir, nuevas fronteras en la frontera interior.

Este es un tema antiguo, llamado por Marx la acumulación originaria: "El secreto de la acumulación originaria tuvo su origen en la apropiación de los bienes comunes" (Marx, en Camus, 2016). Entonces, lo que sucede en Patagonia-Aysén -en nombre de la Naturalezaes un proceso que reemplaza a una política pública previa (e histórica) de incentivos en la colonización y en la entrega de Título Gratuitos para esos colonos -que en nombre de la Patria- ocupaban esos australes territorios caracterizados, como vimos, por una naturaleza salvaje e inhóspita. Aquella ocupación histórica cuyas ocupaciones sin bien tenían asociada un régimen legal de propiedad privada, en la práctica funcionaban bajo la lógica de bienes comunes en tanto el bosque en general era usado para leña y construcción, las montañas eran el espacio para sus "veranadas" o se establecían códigos de conducta y de prácticas de espacios abiertos y solidaridad al sentirse parte de un proceso en curso: hacer patria.

Desde esta perspectiva, lo que ha venido sucediendo en relación al tema de los bienes comunes dice relación con lo que Harvey, retomando a Marx, denomina la "acumulación por desposesión". Aunque, como nos ilustra el propio Harvey (2004), este es un proceso global donde el capital ha volcado a través de mecanismos financieros el lenguaje del despojo, en Patagonia-Aysén ello es visible precisamente desde el proceso de culminación de prácticas que se sustentaban en los bienes comunes por lógicas clásicas de propiedad privada:

\footnotetext{
"Yo recuerdo -nos indicó un poblador del área circundante del Lago General Carrera- que este era un sector que tu podías transitar sin mayores problemas. Tú simplemente salías del pueblo y caminabas por la pampa, no había cercos, no había mayores restricciones de ningún tipo, tú caminabas, pasabas normalmente, no se pedía permiso a nadie, porque no era muy común. Por esta ruta uno iba al cementerio viejo, cruzando algunos alambrados, pero hoy día si tú quisieras hacer lo mismo tendrías que pasar por un montón de gente, pedir permiso a muchas personas y muchas personas te restringen también el acceso, hay lugares en que tú simplemente no puedes pasar. Por ejemplo, no puedes pasar por medio de un predio de cerezas, tienes que pedir permiso o tomar caminos vecinales o las servidumbres de paso que también se han ido perdiendo..." (Valko, Lago G. Carrera, 2016).
}

El turismo, y en esto la (nueva) Naturaleza ha jugado nuevamente un rol central en PatagoniaAysén, ha sido otro de los dispositivos claves de despojo en tanto ha requerido de espacios donde se pueda invertir en caso de sobreacumulación. Los llamados espacios "naturales" han jugado un rol articulador en tal proceso de sobreacumulación y la aparición de numerosos lodge de pesca, de hoteles boutique, 
entre otros, han encauzado los nuevos intereses del capital. Un ejemplo claro de esto es el del proyecto Patagonian land, Premium lands in the southern end of South America, que es de "una empresa inversora chilena-norteamericana, dedicada a los rubros de salud y turismo... [que realiza] proyectos únicos, caracterizados por su excelente ubicación y con especial preocupación por la naturaleza y su conservación" (www. patagonianlandconservationtrust.org) ${ }^{9}$.

Entre los distintos proyectos que tiene la empresa en la zona hay uno llamado Isla de Bahía Exploradores, ubicado cercano al kilómetro 80 del camino. El proyecto, de acuerdo a sus propias palabras:

\footnotetext{
“...está orientado a particulares o empresas del área de turismo, que deseen contar con un predio en una zona única del mundo, ya sea con fines habitacionalesrecreacionales, o con el fin de desarrollar proyectos en el área de turismo de intereses especiales o ecoturismo" (www.patagonianlandconservationtrust.org) ${ }^{10}$.
}

Por último, en este proceso de privatización de la Naturaleza y por ende del fin de los bienes comunes en Patagonia-Aysén, el anuncio de la creación de una Red de Parques de la Patagonia ha venido a consolidar el proceso previamente indicado. En ello, como ha expresado Neumann

9 Como ha expuesto Saenz y Rodríguez(2015) y Rodríguez et al (2017, 26): "El asentamiento de los modelos de liberalización económica se traduce en la fragmentación racional y social del espacio (Sáenz, 2015), con la presencia renovada de empresas ligadas a las industrias del ocio (lodges, escalamiento, caminatas, pesca, contemplación), y el surgimiento de actores invisibles, anónimos y deslocalizados, que dan cuenta de poderes políticos y económicos con capacidad de restringir actividades tradicionales, usar y transformar los territorios a distancia".

10 Al momento de escribir esto nos encontramos investigando dos aspectos colaterales del proceso de sobreacumulación. Uno tiene que ver con que el despojo no ha sido radical, es decir, que algunos descendientes de pobladores antiguos han optado por mantenerse en sus predios viendo en el turismo un posibilidad de evitar la migración forzada que implica la decadencia del rubro ganadero en la zona. En segundo lugar, ha sido preguntarse si a partir de este proceso es factible hablar de gentrificación rural.
(2005) el proceso de construcción de una nueva naturaleza es aún más evidente, ya que estas zonas se producen desde una arquitectura de comprensión donde "lo natural" se funde precisamente con lo no humano, insistiendo en la separación cultura/naturaleza. La Red es una combinación de las áreas públicas que sumadas a las tierras donadas por empresarios privados, especialmente el conservacionista, recientemente fallecido, Douglas Tompkins, han permitido para Patagonia-Aysén, como han expresado las propias autoridades, "proteger nuestro patrimonio natural" (MMA, 2016/2018). De este modo, el proceso de turistificación, de transacción de tierras (visto en segmento anterior) y la creación de la Red, han llevado a "cercar" áreas que algunos años atrás eran bienes comunes:

\footnotetext{
"Antes una gallina iba a poner por allá y ahora ya no se puede pasar, hay hasta cámaras y alambres eléctricos, eso no se veía en ningún lado... acá no nos dejan pasar, capaz que nos meten preso, no como antes que uno pasaba. Para mí, no estoy de acuerdo de que porque uno pase, se va a llevar la tierra" (Ramón, Lago G. Carrera, 2016).
}

El carácter de "museo" que adquiere la Naturaleza en Patagonia-Aysén impone finalmente que ella reciba un rol marcadamente esencial o sustancial que termina por ratificar una vez más, que fue como iniciamos el presente texto, la separación entre sujeto y objeto, es decir, como ha expuesto Descola, la Naturaleza solo adquiere sentido "en oposición a las obras humanas, ya se prefiera dar el nombre de cultura, sociedad o historia..." $(2012,31)$.

Antes Naturaleza inútil, hoy Naturaleza mágica (Núñez, Aliste y Bello, 2017b). Estos regímenes de historicidad o, siguiendo a Descola (2012), esquemas ontológicos en la relación culturanaturaleza, vienen a ratificar que las nuevas formas de relación con la Naturaleza en Patagonia-Aysén no es un asunto neutro; por 
el contrario, tiene profundas raíces políticas y estrechamente asociadas a lógicas capitalistas y la consecuente privatización del Estado.

Como es posible leer en el trabajo de Libuy (2016) el sentido de "prohibido y ajeno" ya no solo se instala en el bosque sino se extiende al paisaje en general:

\begin{abstract}
"Cuando íbamos a ese lado (por donde está el club de yates) a pescar, ibamos a tomar mate, a buscar leña. En cambio ahora todo tiene dueño (...) La fábrica de alfombras ahora una no puede ir ni a mirar porque son para los puros turistas. Las playas también dicen que las compraron la piscicultura. Nosotros vamos para el lado donde todavía no prohíben bañarse" (Bertina en Libuy, 2016).
\end{abstract}

\section{Conclusión}

Hemos expuesto una serie de impactos o procesos de cambio que han surgido en la nueva relación cultura-naturaleza en PatagoniaAysén. Como fue nuestro interés demostrar, la Naturaleza no existe en sí misma sino como proyección valórica e identitaria de procesos socio-temporales que reflejan consensos significantes. En otras palabras, hemos formulado que la nueva retórica geográfica que expresa socialmente a Patagonia-Aysén desde 1990 representa una re-apropiación de la Naturaleza (Leff, 2004, Laurín, 2015) y una nueva matriz interpretativa en torno a ella.

La Naturaleza representada como pureza universal no solo es un "escenario" o "museo" que es observado por actores sociales, es también un diálogo y una co-fabricación de sentidos que termina impactando las formas y los modos en que la comunidad se desenvuelve en su habitar (espacio vivido). partir de la relación con otros significantes: el capital, como vimos, pero también con las prácticas sociales cotidianas. En el fondo, los discursos del conocimiento formal y de las maneras de pensar las intervenciones en favor de determinados discursos del desarrollo, lo hacen también a través de las prácticas espaciales (Aliste y Rabi, 2012).

En efecto, los antiguos "colonos" no son indiferentes a la nueva relación culturanaturaleza $\mathrm{y}$, por lo mismo, se movilizan identitaria y cotidianamente hacia lenguajes socio-territoriales que buscan ser coherentes con el nuevo devenir de tipo "verde". Así, en Patagonia-Aysén "lo humano" no es posible ser comprendido de manera autónoma de la "selva virgen", ya que ella se entrelaza con la cultura modificando su devenir, generándose una suerte de hibridez social donde cultura y naturaleza se influyen y median mutuamente. En palabras de Latour:

\footnotetext{
"Los entramados socio-naturales se construyen a partir de series proliferantes de cuasi-objetos, ensamblajes relacionales configurados en red, ubicados a medio camino entre los polos de la Naturaleza, por una parte, y la Cultura, por el otro. Son al mismo tiempo ambas cosas y ninguna, y a pesar de todo, son socio-ecológicamente significativos y políticamente performativos" (Latour, 2008).
}

\section{Estos entramados y ensamblajes forman socio-naturalezas que definen, coreografían y sostienen la vida y las prácticas cotidianas (Swyngedouw, 1996; 2015) en un "proceso ontológicamente fluido, en que múltiples mundos potenciales cobra forma de modo simultáneo" (Sepúlveda y Sundberg, 2015).}

¿Qué es, entonces, la (nueva) Naturaleza en Patagonia-Aysén? De acuerdo a la hipótesis desarrollada, es despliegue, es una posibilidad y un horizonte de sentido finito, móvil, en tránsito sentidos de la Naturaleza se desenvuelven a 
que de tanto en tanto se constituye en mito social. Como plantea Todorov (2013), la memoria es olvido y, tal vez por lo mismo, requiere de arquitecturas sociales que la definan, que le den un significado, un sentido. El sentido de quemar el bosque para alcanzar la civilización, el significado de conservar los bosques para llegar al desarrollo. Aquellas arquitecturas sociales, como hemos visto, son una nueva expresión de perspectivas coloniales, pero en clave ECO, por lo que lo verde en Patagonia-Aysén no es separable de los códigos políticos y de poder con que se posicionan hacia la sociedad.
De este modo, consideramos que es vital en los estudios de geografía analizar que el o los sentidos de la (nueva) Naturaleza en PatagoniaAysén supone también considerar la experiencia (temporalidad) o radical historicidad del espacio como soporte esencial de la interpretación que el sujeto social se hace de él. En otras palabras, la interrogación del espacio implicará tener en consideración tanto la perspectiva comprensiva del sujeto como, a su vez, "la situación hermenéutica a la que pertenece" aquella comprensión.

\section{Bibliografía}

Alimonda, H. 2011. La naturaleza colonizada. Buenos Aires, Ediciones Ciccus/Clacso.

Aliste, E. y Urquiza, A. 2010. Medio ambiente y sociedad. Conceptos, metodologías y experiencias desde las ciencias sociales y humanas. Santiago, RiL Editores.

Aliste, E. y Rabi, V. 2012. "Concebir lo socio-ambiental: representación y representatividad de los discursos sobre el desarrollo". Revista Polis 32: 307-327.

Aliste, E. y Núñez, A. 2015. "Las fronteras del discurso geográfico: el tiempo y el espacio en la investigación social”. Chungará 47 (42): 287-301.

Arenas, F., Salazar, A., Núñez, A. (Eds.) 2011. El aislamiento geográfico: ¿problema, oportunidad? Santiago, Geolibros.

Ayala, M. y Moritz, T. 2012. El capitalismo verde: otra cara del mismo modelo. Colombia, Corporación Social para la Asesoría y Capacitación Comunitaria (COSPACC).

Azam, G., Bonneuil, C. y Combes, M. 2012. La naturaleza no tiene precio. Lo que oculta la economía verde. Madrid, Clave Intelectual.

Bhabha, H.(Eds.) 2010. Nación y Narración. Buenos Aires, Siglo XXI editores.

Bustos, B., Prieto, M. y Barton, J. 2015. Ecología Política en Chile. Santiago, Editorial Universitaria.

Camus, P.; Hidago, R. 2016. "Y serán desplayados. Recorrido histórico sobre los bienes comunes, pescadores artesanales y control legal del litoral en Chile". Historia Critica. No. 63 - Eneromarzo, 97-116

Casini, S. 2005. "Ficciones de Patagonia: la construcción del sur en la narrativa Argentina y Chilena". University of Kentucky Doctoral Dissertations: 377

Castoriadis, C. 2010. La institución imaginaria de la sociedad.
Buenos Aires, Tusquets Editores.

Castree, N. 1995. "The nature of produced nature". Antípode 27: $12-48$.

Castree, N. 2005. Nature the adventures of a concept. Londres, Routledge.

Deleuze, G. y Guattari, F. 2002. Mil Mesetas. Capitalismo y esquizofrenia, Pre-Textos, Valencia.

Descola, P. 2012. Más allá de la naturaleza y la cultura. Buenos Aires, Amorrortu.

Di Méo, G. y Buléon, P. 2005. L'espace social. Lecture géographique des sociétés. Paris, Armand Colin.

Escobar, A. 2012. Una minga para el posdesarrollo. Colombia, Ediciones desde Abajo.

Foucault, M. 2010. Cuerpo Utópico/Las heterotopías. Buenos Aires, Nueva Visión.

Gadamer, H.G.1999 Verdad y Método. Barcelona, Ed. Sígueme.

García Canclini, N. 2005. Culturas Hibridas. Estrategias para entrar y salir de la modernidad. Buenos Aires, Paidós.

García, G. 1989. "Carretera Longitudinal Austral. La respuesta a un desafío". Revista Chilena de Geopolítica 5 (3): 51-69.

GORE, 2009. Estrategia Regional de Aysén, Gobierno Regional de Aysén.

Gregory, D. 2001. "(Post)colonialism and the production of nature". Social Nature: theory, practice and politics. Castree y Braun (Eds). Blackwell: Oxford, 84-111

Grosfoguel, R. 2016. Del "extractivismo económico" al "extractivismo epistémico" y al "extractivismo ontológico": una forma destructiva de conocer, ser y estar en el mundo. Tabula Rasa. Bogotá, Colombia, No.24: 123-143.

Harvey, D. (2004). El "nuevo" imperialismo. Madrid, Akal. 
Harvey, D. 2014. Seventeenth contradictions and the end of capitalism. Londres, Profile Books.

Huggan, G. y Tiffin, H. 2007. "Green Postcolonialism". Interventions: I. Journal of postcolonial studies 9 (1): 1-1

Jazeel, T. 2014. "Subaltern Geographies: geographical knowledge and postcolonial strategy". Singapore Journal of Tropical Geography 35 (1): 88-103.

Keucheyan, R. 2016. La naturaleza es un campo de batalla. Buenos Aires, Capital Intelectual editores.

Latour, B. 2008. Reensamblar lo social, una introducción a la teoría del actor-red. Buenos Aires, Manantial.

Laurín, A., Núñez, A. 2013. "Frontera, globalización y deconstrucción estatal. Hacia una geografía política crítica. Araucania-Norpatagonia: la territorialidad en debate, 83100.

Laurín, A. 2015. "Los territorios universales del siglo XXI: nueva categoría de la espacialidad (do)minada". Geopolitica (s) Revista sobre estudios de espacio y poder 6 (1): 83-106.

Leff, E. 2004. Racionalidad ambiental: la reapropiación de la naturaleza. Argentina: Siglo XXI editores.

Libuy, M. 2016. Prácticas y representaciones vinculadas al bosque nativo en Aysén en el actual contexto de mercantilización de la naturaleza. Tesis de grado de Antropología, Universidad de Chile.

Lindón, A. y Hiernaux, D. (Eds.) 2010. Los giros de la Geografía Humana. Desafíos y horizontes. México, UAM, Anthropos.

Lindón, A.; Hiernaux, D. (Eds.) 2012. Geografías de 10 imaginario. México, UAM, Anthropos.

Maturana, H. (2009). La realidad ¿objetiva o construida?: fundamentos biológicos del conocimiento. Anthropos, Barcelona.

Ministerio de Medio Ambiente de Chile. 2016/2018. Conservando el patrimonio natural de Chile. Santiago, MMA.

Mellado, L.A. 2015. "La patagonia como versión de una distancia". Alpha (Osorno) 41: 65-7.

Mignolo, W. (Ed.) 2014. Capitalismo y geopolítica del conocimiento. Buenos Aires, Signo.

Neumann, R. 2005. Making political ecology. London: Hodder Arnold.

Nogué, J.; Rufí, J. (Eds.) 2001. Geopolítica, identidad y globalización. Ariel, Barcelona, 256.

Nogué, J.; Romero, J. (Eds.) 2006. Las otras geografías. Valencia, Tirant lo Blanch.

Nogué, J. (Ed.) 2009. La construcción social del paisaje. Biblioteca Nueva, Barcelona.

Núñez, A. 2013. "La historicidad del espacio". Revista de Geografía Norte Grande 54: 3-6.

Núñez, A., Aliste, E. y Bello, A. 2014. "El discurso del desarrollo en Patagonia-Aysén: la conservación y la protección de la naturaleza como dispositivos de una renovada colonización". Scripta Nova 18 (493): 46

Aliste, E., Núñez. A. 2015. "Las fronteras del discurso geográfico: el tiempo y el espacio en la investigación social”. Chungará. Vol. 47, № 42, 287-301.
Núñez, A., Molina, R., Aliste, E., Bello, A. 2016. "Silencios geográficos en Patagonia-Aysén: territorio, nomadismo y perspectivas para re-pensar los márgenes de la nación en el siglo XIX". Revista Magallania. № 2, Vol 44.

Núñez, A., Aliste, E. y Arenas, F. 2017a. "Paisajes en Fuga. Imaginarios y arquitecturas de la Patagonia". Revista AUS, $N^{\circ} 22$, Universidad Austral de Chile.

Núñez, A., Aliste, E., y Bello, A. 2017b. "Discursos Ambientales y Procesos de Fronterización en Patagonia-Aysén (Chile): de los paisajes de la mala hierba a los del bosque sagrado". Fronteiras: Journal of Social, Technological and Environmental Science 6 (1): 198-218.

Quijano, A. 2000. "Colonialidad del poder, eurocentrismo y América Latina". La colonialidad del saber: eurocentrismo y ciencias sociales Lander, E. (Ed.). Buenos Aires: 246-265.

Reyes Herrera, S., y Rodríguez T.o, J. C. 2015. "Proyecto Hidroaysén: capitalismo extractivista, regulación estatal y acción colectiva en la Patagonia". Polis (Santiago) 14(40): 439-467

Ricoeur, P. (2010). Time and narrative (Vol. 3). University of Chicago Press.

Rodríguez T, J.C., Medina H, P., Reyes H, S. 2014. "Territorio, paisaje y marketing global: Imaginarios en la construcción de la Patagonia como marca". Magallania (Punta Arenas) 42 (2): 109123

Rodríguez, J.C., Reyes, S., y Mandujano, F. 2016. "Reconfiguración espacial y modelos de apropiación y uso del territorio en la Patagonia chilena: migración por cambio de estilo de vida, parques de conservación y economía de la experiencia". Revista de Geografía Norte Grande 64: 187-206

Rodríguez, J.C. y Sáenz, J. 2017. "De Colonos a 'vivientes'. Una nueva Categoría social en la Patagonia rural Chilena" Revista San Gregorio 18: 20-33.

Romero, H. 2014. "Ecología política y represas: elementos para el análisis del Proyecto HidroAysén en la Patagonia chilena", Revista Geografía Norte Grande 57: 161-175.

Sáenz, J. y Rodríguez, J. 2015. "Territorios en mutación. Superación y desplazamiento de las fronteras interiores en la Patagonia Chilena". Revista Márgenes, Espacio Arte Sociedad 17 (12):51-61.

Said, E. 2010. Orientalismo. Barcelona, Debolsillo.

Sassen, S. 2015. Expulsiones. Brutalidad y complejidad en la economía global. Buenos Aires, Katz.

Sepúlveda, C. y Sundberg, J. 2015. "Apertura Ontológica, multiplicidad y performación...". Ecología Política en Chile. Bustos, B., Prieto, M. y Barton, J (Eds). Santiago: 67-84.

Serje, M. 2011. El revés de la nación: territorios salvajes, fronteras y tierras de nadie. Bogotá, U. de Los Andes.

Smith, N. 1984. Uneven Development. Nature, Capital and the production of Space. Oxford, Basil Blackwell.

SUBDERE. 2008. Diagnóstico y propuesta para territories aislados. Subsecretaría de Desarrollo Regional, Gobierno de Chile.

Swyngedouw, E.1996. The city as a hybrid: on nature, society and ciborg urbanization. Capitalism Nature Socialism, 7(2), 65-80. 
Swyngedouw, E. 2015. La naturaleza no existe. La sostenibilidad como síntoma de una planificación despolitizada. Argentina, Puente Aéreo ediciones.

Ther, F. 2012. "Antropología del territorio". Polis 11 (32): 492510.

Todorov, T. (2012). La conquista de América. El problema del otro. México, Siglo XXI.

Todorov, T. (2013). Los usos de la memoria. Signos, Santiago.

Urrutia, S. 2017. "Carretera Austral: ¿Integración o fronterización?... (1973-1990)". En Imaginarios geográficos y discursos de frontera. Aysén desde el texto de la nación. Núñez, A., Aliste, E., Osorio, M. y Bello, A. (Eds.) Coyhaique/Santiago: 239-262.

Vergara, Nelson (2010). "Saberes y entornos: notas para una epistemología del territorio". Alpha 31: 163-174

Von Mentz, B. 2012. La relación hombre-naturaleza. México, Siglo XXI Editores.
Zizek, S. 2013. Repetir Lenin. Madrid, Akal.

Zusman, P., R. Haesbaert, H., Castro, H., Adamo, S. 2011. Geografías Culturales. Buenos Aires, UBA.

\section{Archivos}

AMTC, 1941-1948. Archivo de Tierras y Colonización. Ministerio de Bienes Nacionales.

\section{Prensa digital}

"Homenaje inauguración Carretera Austral", El Diario de Aysén, 2/1982, Coyhaique.

"Douglas Tompkins". La Tercera 13/07/97, Santiago, Chile.

"Inauguran la Red de Parques de la Patagonia". BBC Mundo, 17/03/2017.

“Patagonia Hot”. 2014. Revista Capital. 10/17/2014. 
